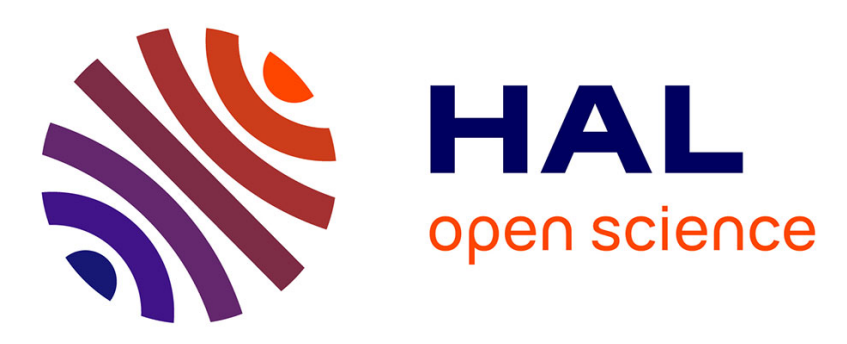

\title{
Hardware-in-the-loop simulator for stability study in orthogonal cutting
}

Iker Mancisidor, Xavier Beudaert, Ainhoa Etxebarria, Rafael Barcena, Jokin

Munoa, Josu Jugo

\section{- To cite this version:}

Iker Mancisidor, Xavier Beudaert, Ainhoa Etxebarria, Rafael Barcena, Jokin Munoa, et al.. Hardwarein-the-loop simulator for stability study in orthogonal cutting. Control Engineering Practice, 2015, 44, pp.31-44. hal-02114950

\section{HAL Id: hal-02114950 \\ https://hal.science/hal-02114950}

Submitted on 30 Apr 2019

HAL is a multi-disciplinary open access archive for the deposit and dissemination of scientific research documents, whether they are published or not. The documents may come from teaching and research institutions in France or abroad, or from public or private research centers.
L'archive ouverte pluridisciplinaire HAL, est destinée au dépôt et à la diffusion de documents scientifiques de niveau recherche, publiés ou non, émanant des établissements d'enseignement et de recherche français ou étrangers, des laboratoires publics ou privés. 


\title{
HARDWARE-IN-THE-LOOP SIMULATOR FOR STABILITY STUDY IN ORTHOGONAL CUTTING
}

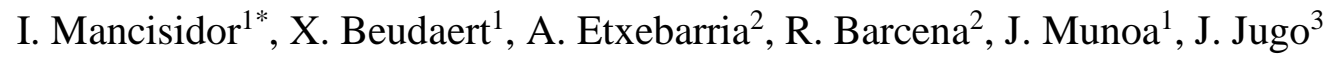 \\ ${ }^{1}$ Dynamics and Control department, IK4-Ideko, 20870 Elgoibar, Basque Country, Spain \\ ${ }^{2}$ Department of Electronic Technology, University of the Basque Country, 48013 Bilbao, Basque Country, Spain \\ ${ }^{3}$ Departent of Electricity and Electronics, University of the Basque Country, 48013 Bilbao, Basque Country, Spain
}

\begin{abstract}
The self-excited vibrations due to the regenerative effect, commonly known as chatter, are one of the major problems in machining processes. They cause a reduction in the surface quality and in the lifetime of mechanical elements including cutting tools. Furthermore, the experimental investigations of chatter suppression techniques are difficult in a real machining environment, due to repeatability problems of hard to control parameters like tool wear or position dependent dynamic flexibility. In this work, a mechatronic hardware-in-the-loop (HIL) simulator based on a flexible structure is proposed for dimensionless study of chatter in orthogonal cutting. Such system reproduces experimentally, on a simple linear mechanical structure in the laboratory, any stability situation which can be used to test and optimize active control devices. For this purpose, a dimensionless formulation is adopted and the delay related to the phase lag of the actuator and the controller employed on the HIL is compensated.
\end{abstract}

Keywords: chatter; orthogonal cutting; stability; hardware-in-the-loop; active control.

\footnotetext{
* Corresponding author. Tel.: +34 943748000. Email address: imancisidor@ideko.es (I.Mancisidor)
} 


\section{INTRODUCTION}

The presence of self-excited vibration, also known as chatter, in machining processes is a classic problem that limits material removal capability. The presence of these vibrations on machines is disastrous since they prevent obtaining the required surface finishes and decrease the lifetime of tools and mechanical components of the machine.

The principal reason of chatter onset is the regenerative effect, which was defined by Tobias [1] and Tlusty [2] as a complex phenomenon affected by machining characteristics (spindle speed, depth of cut...) and dynamic properties of the machine (stiffness and mass distribution, damping...). Later on, Merrit [3] presented the problem as a feedback loop, clarifying the understanding of the problem. All these theoretical and experimental developments were focused on continuous processes such as turning operations. More recently, studies about milling processes have been performed ([4]-[6]). In these investigations, the stability lobe diagrams define the limiting values for machining parameters in order to assure a stable cut. Therefore, such diagrams are usually employed to optimize the material removal rate.

Many researchers have proposed methods to avoid regenerative chatter for many years. Some of them are based on changing the spindle speed or tool geometry modification, while other authors proposed the distortion of the regenerative effect by a continuous spindle speed variation (SSV) ([4],[6]). One of the most employed methods is to locate a tuned vibration absorber in the structure ([7], [8]). Passive devices can be appropriate in many cases, but they present limitations when dynamic characteristics can vary considerably. Active control can overcome these limitations due to its adaptability to changing conditions ([9]-[14]). Generally, such active actuators are based on the introduction of a controlled force associated to the measurement of a parameter related to the vibration. In this way, a dynamically correlated external energy is 
applied into the structure of the machine.

Nonetheless, the optimization of these chatter suppression methods requires a big number of factual experiments. These tests may be very problematic, due to the large number of uncertain machining parameters (tool wear, material properties ...) and unavoidable cutting tests. Furthermore, the chatter characterization process always forces the whole system to reach the stability limit and this may decrease the lifetime of several elements of the machine tool.

In this context, this work proposes the development of a mechatronic Hardware-In-the-Loop (HIL) system for simulating an orthogonal cutting process. In this way, such HIL simulator reproduces experimentally, on a simple mechanical structure, an equivalent cutting process where regenerative chatter can appear depending on the cutting parameters. This kind of systems can be used for testing the influence of different parameters inside the chatter formulation and active and passive chatter suppression methods can be experimentally tested and optimized by non-destructive testing. Nevertheless, such HIL simulation systems include some disadvantages. On the one hand, complex systems, where several modes can interact, cannot be reproduced accurately yet. On the other hand, only the vibration level is analysed, while other parameters such as surface finishing or chip breakage quality are not taken into account.

HIL systems have been widely employed in several industries such as automotive ([15]). However, in manufacturing, few studies have been conducted based on such simulators. Different authors proposed the construction of different HIL simulators for reproducing machining processes ([16], [17]). However, they were built for a particular case and the delay that usually exists in mechatronic systems was neglected. The non-consideration of such delay changes drastically the regenerative effect and thus, the obtained results are not correlating properly with the theoretical stability diagrams. 
The present work describes a HIL system for orthogonal cutting operations. It permits the simulation of machining process where the stability is dominated by a single mode. More complex machining operations, such as milling, could be simulated by means of a structure with more than one DOF, using more shakers to simulate complex dynamic forces in three dimensions and adapting the algorithm of the controller [18]. However, the simulation of operations where more than one mode interacts in the same frequency range is a limitation for the system. In these cases, the ratio between natural frequencies and dynamic flexibilities of different modes produce intricate stability lobes diagrams [5].

A dimensionless formulation is proposed in order to perform the dimensional analysis based on Fourier's principle of dimensional homogeneity, which states that an equation linking physical quantities must be dimensionally homogeneous [19]. The HIL system provides the possibility of simulating equivalent conditions of any orthogonal cutting process by adjusting the HIL relative damping to the damping of the desired system. A methodology to adjust this damping and the non-negligible delay is presented. Accurate results can be obtained and the experimental tests to optimize active control strategies can be extremely simplified.

\section{REGENERATIVE CHATTER IN ORTHOGONAL CUTTING PROCESS}

A brief explanation of the regenerative effect is offered in this section. First, the problem is mathematically formulated and then, a dimensionless approximation of this problem is proposed.

\subsection{Formulation of the Regenerative Effect}

Machine tool chatter vibrations result from a self-excitation mechanism in the generation of chip thickness during machining operations ([1]-[4]). Initially, cutting forces excite the structural modes of the machine tool-workpiece system and a wavy surface $(x(t-\tau))$ is left on the workpiece. 
In next revolution, this wavy surface is removed and, at the same time, a wavy surface $(x(t))$ is left owing to structural vibrations. This process is clearly shown in a groove turning operation (see Fig. 1).

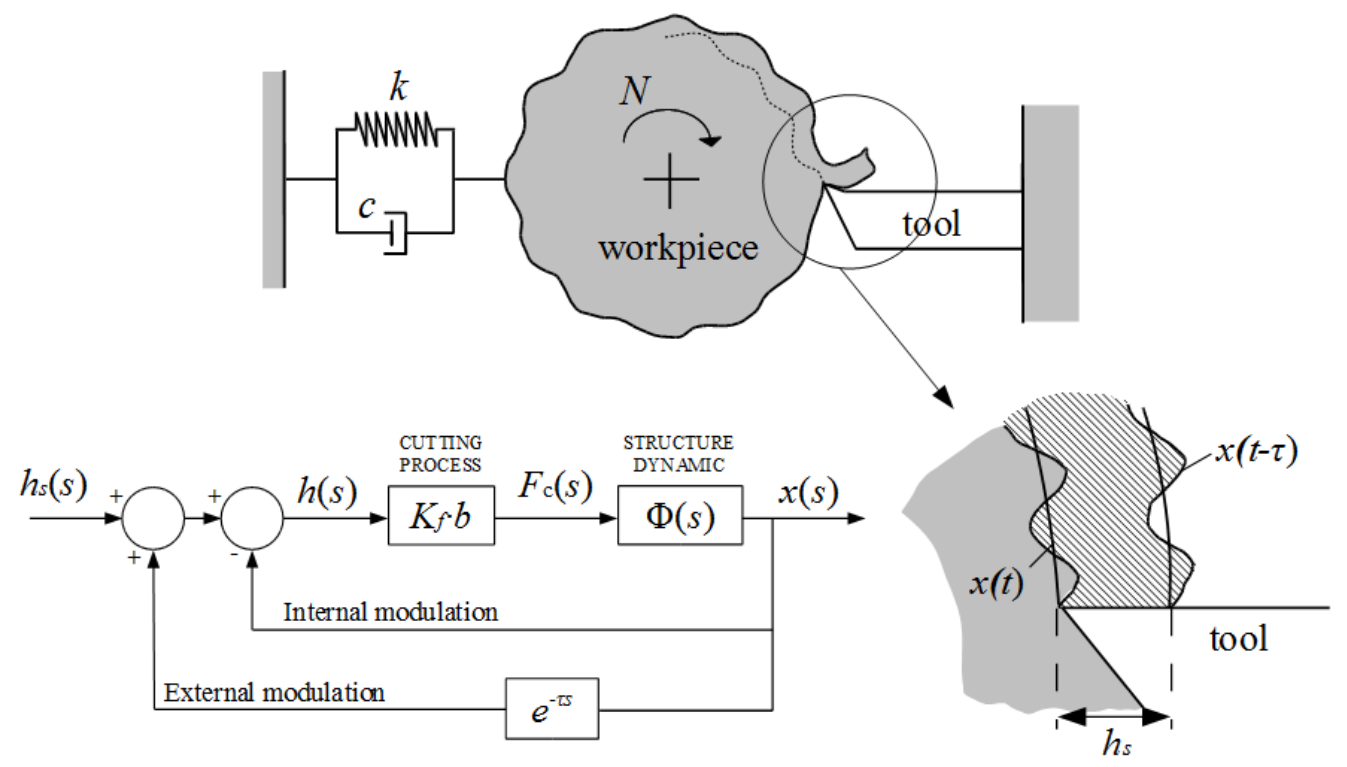

Fig. 1. Regenerative chatter vibrations in orthogonal cutting process.

Depending on the phase shift between two successive waves, the maximum chip thickness $h$ may exponentially grow. The growing vibrations increase cutting forces $F_{\mathrm{c}}(t)$, which depend on the chip thickness, and the process can become unstable. The general chip thickness can be expressed as follows:

$$
h(t)=h_{s}-[x(t)-x(t-\tau)]
$$

where $h_{s}$ is the nominal feed per revolution, and $[x(t)-x(t-\tau)]$ is the dynamic chip thickness produced by actual vibrations $(x(t))$ and previous period vibrations $(x(t-\tau))$. It is well known that the variable cutting force $F_{\mathrm{c}}(t)$ can be considered proportional to the frontal chip area, which is defined by the the chip thickness $h(t)$ and the depth of the cut $b$. In the reality the cutting force is more complex with different possible non linearities [20] and additional terms proportional to the 
vibration speed or acceleration [21]. These additional terms can describe the process damping related to the interaction between vibration waves and tool flank wear. However, the main regenerative term can be modelled with this simple formulation.

$$
F_{\mathrm{c}}(t)=K_{f} \cdot b \cdot h(t)
$$

where $K_{f}$ is the cutting coefficient of the process.

Assuming that the system has a dominant mode in the radial direction and neglecting the process damping [21], the equation of motion can be defined as

$$
m \cdot \ddot{x}(t)+c \cdot \dot{x}(t)+k \cdot x(t)=F_{\mathrm{c}}(t)=K_{f} \cdot b \cdot h(t)
$$

where $m$ is the mass, $c$ is the damping coefficient and $k$ is the stiffness of the system.

\subsection{Stability of the process}

The chatter vibration system can be represented by the block diagram proposed by Merrit [3] and shown in Fig. 1, where parameters are shown in Laplace domain and $\Phi(s)$ defines the transfer function between the cutting force and the displacement.

$$
\Phi(s)=\frac{x(s)}{F_{c}(s)}=\frac{1}{m s^{2}+c s+k}=\frac{\omega_{\mathrm{n}}^{2}}{k\left(s^{2}+2 \xi \omega_{\mathrm{n}} s+\omega_{\mathrm{n}}^{2}\right)}
$$

$\omega_{\mathrm{n}}$ and $\xi$ are natural frequency and relative damping of the system. The relative damping is the ratio between the actual damping and the critical damping coefficient $\left(c / c_{\mathrm{c}}\right)$, being $c_{\mathrm{c}}{ }^{2}=4 m k$. If equation (4) and the Laplace transform of (2) are substituted in the Laplace transform of (1), the resulting transfer function between the vibration and the reference chip thickness becomes:

$$
\frac{x(s)}{h_{s}(s)}=\frac{K_{f} \cdot b \cdot \Phi(s)}{1+K_{f} \cdot b \cdot \Phi(s)\left(1-e^{-\tau s}\right)}
$$


The characteristic equation of such closed loop is then

$$
1+K_{f} \cdot b \cdot \Phi(s)\left(1-e^{-\tau s}\right)=0
$$

The dynamic of the structure $\Phi$ can be analysed for a critically stable case. Hence, $s=\mathrm{i} \omega_{\mathrm{c}}$ is considered, where $\omega_{\mathrm{c}}$ is the chatter frequency. Additionally, the ratio of chatter frequency to natural frequency $\left(\omega_{\mathrm{c}} / \omega_{\mathrm{n}}\right)$ is defined as $\lambda$.

$$
\Phi\left(\mathrm{i} \omega_{\mathrm{c}}\right)=G+\mathrm{i} H=\frac{1-\lambda^{2}}{k\left[\left(1-\lambda^{2}\right)^{2}+4 \xi^{2} \lambda^{2}\right]}+\mathrm{i} \frac{-2 \xi \lambda}{k\left[\left(1-\lambda^{2}\right)^{2}+4 \xi^{2} \lambda^{2}\right]}
$$

If equation (6) is divided into real and imaginary parts and the equation (7) is taken into consideration,

$$
\left\{1+K_{f} b\left[G\left(1-\cos \omega_{\mathrm{c}} \tau\right)-H \sin \omega_{\mathrm{c}} \tau\right]\right\}+\mathrm{i}\left\{K_{f} b\left[G\left(\sin \omega_{\mathrm{c}} \tau\right)+H\left(1-\cos \omega_{\mathrm{c}} \tau\right)\right]\right\}=0
$$

If real and imaginary parts of equation (8) are set equal to zero, some relations between parameters can be obtained. From the imaginary part, the next expression is obtained:

$$
\frac{H}{G}=\frac{\sin \omega_{\mathrm{c}} \tau}{\cos \omega_{\mathrm{c}} \tau-1}
$$

Analysing the real part, the limiting value of the depth of cut depending on the chatter frequency is achieved. Equation (9) is used to simplify the resulting expression (10).

$$
\begin{aligned}
& 1+K_{f} b\left[G\left(1-\cos \omega_{\mathrm{c}} \tau\right)-H \sin \omega_{\mathrm{c}} \tau\right]=0 \\
& b_{\lim }=\frac{-1}{2 \cdot K_{f} \cdot G\left(\omega_{\mathrm{c}}\right)}
\end{aligned}
$$

Equation (11) shows the limiting depth of cut as a function of the chatter frequency $\omega_{c}$. As the 
depth of cut should always be positive, the absolute minimum stable depth of cut occurs at the maximum negative value of $G\left(G_{\min }\right)$, when $\lambda^{2}=1+2 \xi$

$$
b_{\text {min }}=\frac{-1}{2 \cdot K_{f} \cdot G_{\min }\left(\omega_{\mathrm{c}}\right)}=\frac{2 k \xi(1+\xi)}{K_{f}}
$$

Once the relation between the limiting depth of cut and chatter frequency is obtained, the relation between the chatter frequency and the spindle rotation frequency $\omega$ can be studied. From the imaginary part of equation (8), the phase shift of the dynamic transfer function $(v)$ is defined from equation (7):

$$
\tan v=\frac{H}{G}=\frac{-2 \xi \lambda}{\left(1-\lambda^{2}\right)}
$$

In addition, from equation (9):

$$
\tan v=-\frac{\cos \frac{\omega_{\mathrm{c}} \tau}{2}}{\sin \frac{\omega_{\mathrm{c}} \tau}{2}}=\tan \left(\frac{\omega_{\mathrm{c}} \tau}{2}-\frac{3 \pi}{2}\right)
$$

and considering that phase shift $(v)$ changes between $-\pi / 2$ and $-\pi$ when the real part is negative:

$$
\omega_{\mathrm{c}} \tau=2 v+\left(2 k_{u}+3\right) \cdot \pi
$$

Note that, if $\varepsilon$ is defined as the phase difference between successive ondulations or waves on the workpiece surface and $k_{\mathrm{u}}$ is the number of complete ondulations during one revolution period $\tau$,

$$
\omega_{\mathrm{c}} \tau=2 \pi \cdot k_{\mathrm{u}}+\varepsilon \Rightarrow \tau=\frac{2 \pi \cdot k_{\mathrm{u}}+\varepsilon}{\omega_{\mathrm{c}}}
$$


The phase shift between successive ondulations varies between $2 \pi$ and $\pi$. By combining equations (13), (15) and (16), a relation between the system transfer function and $\varepsilon$ can be obtained:

$$
\varepsilon=2 \nu+3 \pi=2 \cdot \arctan \left(\frac{-2 \xi \lambda}{\left(1-\lambda^{2}\right)}\right)+3 \pi
$$

Therefore, the relation between the chatter frequency and the spindle rotation frequency $\Omega$ is obtained:

$$
\Omega=\frac{2 \pi}{\tau}=\frac{2 \pi \omega_{c}}{2 \pi \cdot k_{\mathrm{u}}+\varepsilon}
$$

Stability lobes diagram can be calculated from the previous relations. First, the chatter frequency range is specified and a sweep of these frequencies is performed. For each frequency, the limiting depth of cut is calculated by equation (11) and different tooth passing frequencies are obtained for different $k_{\mathrm{u}}$ values by equation (18). In this way, the relation between the limiting depth of cut and tooth passing frequencies is obtained, which is reflected in the stability lobes. The diagram representing the chatter frequency as a function of the spindle speed is also employed to analyse the process.

\subsection{Dimensionless study}

A dimensionless formulation can be developed for single DOF systems ([1], [21]). In orthogonal cutting, seven variables can be defined. Three of them are related in the machining process: cutting coefficient $\left(K_{f}\right)$, spindle speed $(N)$ and depth of cut $(b)$. Three other variables can be obtained from the dynamics: mass $(m)$, damping $(c)$ and stiffness $(k)$. Finally, when the critical stability is studied the chatter frequency $\left(\omega_{c}\right)$ is generated. If the dimensional analysis is 
applied [19], four dimensionless variables are required for its general study. In this work, the following four dimensionless parameters have been defined: relative damping ratio $\xi$, normalised chatter frequency $\lambda$, normalised depth of cut $\mu$ and normalised rotation frequency $\beta$.

$$
\begin{aligned}
& \xi=\frac{c}{c_{\mathrm{c}}}=\frac{c}{2 \sqrt{m k}}=\frac{c}{2 m \omega_{\mathrm{n}}} \\
& \lambda=\frac{\omega_{\mathrm{c}}}{\omega_{\mathrm{n}}} \\
& \mu=\frac{b_{\lim }}{b_{\min }}=\frac{K_{f} \cdot b_{\lim }}{2 k \xi(1+\xi)}=-\frac{\left(1-\lambda^{2}\right)^{2}+4 \xi^{2} \lambda^{2}}{4 \xi(1+\xi)\left(1-\lambda^{2}\right)}=\mathrm{f}_{1}(\xi, \lambda) \\
& \beta=\frac{\Omega}{\omega_{\mathrm{n}}}=\frac{2 \pi \lambda}{\left(2 k_{u}+3\right) \cdot \pi+2 \cdot \arctan \left(\frac{-2 \xi \lambda}{\left(1-\lambda^{2}\right)}\right)}=\mathrm{f}_{2}\left(\xi, \lambda, k_{\mathrm{u}}\right)
\end{aligned}
$$

From these parameters, a stability diagram between the normalised depth of cut $\mu$ and the normalised rotation frequency $\beta$ is created, scanning the normalised chatter frequency $\lambda$ for a defined relative damping $\xi$. For each value of normalised chatter frequency, normalised depth of cut and normalised rotation frequency are obtained for different $k_{\mathrm{u}}$ (equations (21) and (22)). On the other hand, a dimensionless chatter frequency chart between $\lambda$ and $\beta$ can also be created considering only equation (22).

These dimensionless stability diagrams have the advantage of allowing comparisons among different machining conditions for systems with one dominant mode with the same damping ratio $\xi$. In this way, the stability study turns out to be more general and independent from machining circumstances. The absolute limit depth of cut is always 1 and only the damping should be adapted to the analysed cutting process in order to obtain the correct lobe shape (see 
Fig. 2)
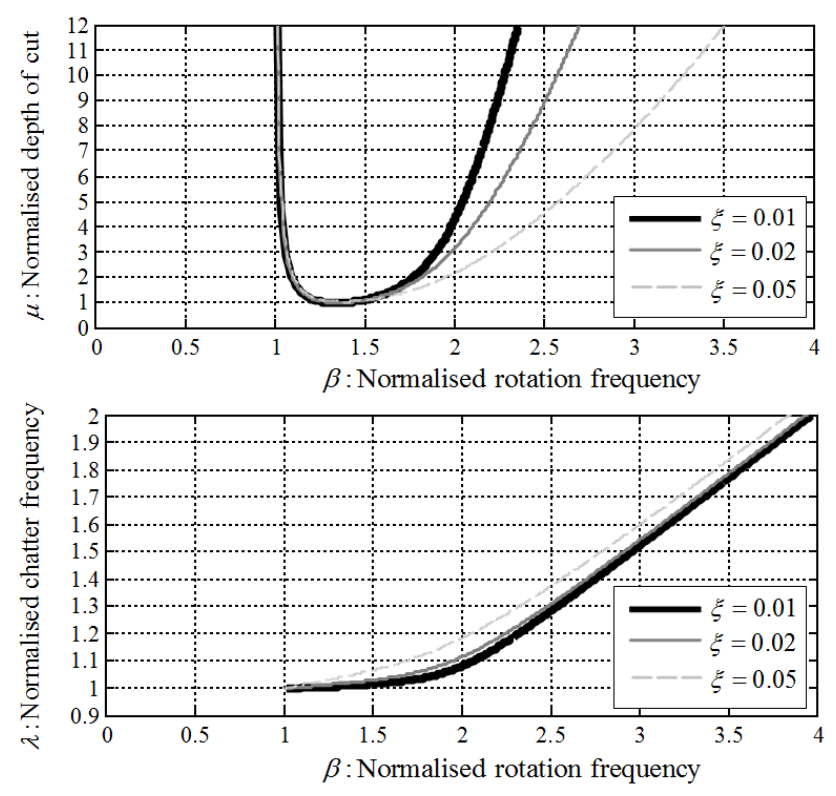

Fig. 2. Dimensionless stability diagrams for three different damping ratios.

\section{DESIGN OF THE HARDWARE-IN-THE-LOOP CHATTER DEMONSTRATOR}

The regenerative feedback model of chatter presented in the previous section has been implemented in a HIL demonstrator. The dynamic of the machine $\Phi(s)$ is represented by a simple mechanical structure, while a shaker is used to apply the variable cutting force $F_{\mathrm{c}}(t)$ on the system. Previous works ([16], [17], [18]) proposed the employment of a simple beam, however, in this kind of system damping is mainly defined by the clamping system and is thus based on dry friction. Therefore, non-linearities appear depending on the clamping force and the dynamic force values.

In the present work, this drawback is overcome by the employment of a linear flexure. On the one hand, stiffness is defined by the structure itself and is independent from the clamping. On the other hand, damping is provided by means of eddy currents which introduce a pure linear viscous 
damping. The achieved linearity facilitates testing considerably.

A collocated force sensor and displacement sensor installed on the structure provide the force $F(t)$ and vibration displacement $x(t)$ measurements. A fast processor, included on a programmable automation controller, calculates the simulated cutting force $F_{\mathrm{c}}(t)$ in real-time. The whole scheme is presented in Fig. 3.

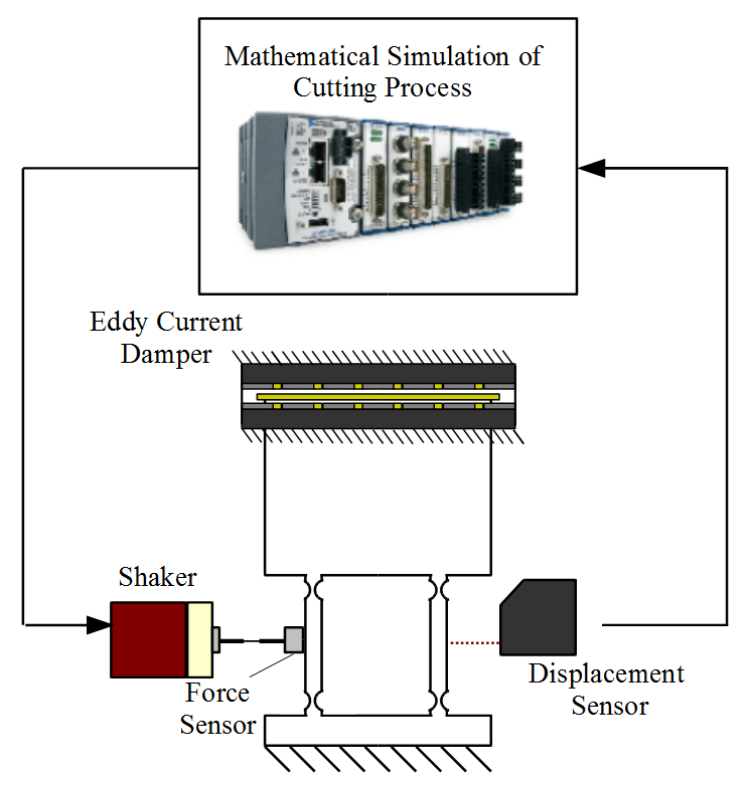

Fig. 3. HIL chatter demonstrator scheme.

\subsection{Mechanical Design}

It is well-known that the excitation of flexible structures near their natural frequencies is very difficult for shakers due to the deterioration of the force/voltage $(\mathrm{F} / \mathrm{V})$ ratio. This fact is very important for this simulator, considering that chatter frequencies are normally in the vicinity of the resonant frequencies of the mechanical structure.

The deteriorated F/V ratio could be avoided by a stiffness increase, although this would raise the natural frequencies of the structure. If the frequencies of the structure become too high, the delay due to the actuator and the controller sampling period could lead to phase differences 
between the signals of the closed loop.

Therefore, a sufficiently flexible flexure has been designed to maintain the natural frequencies low enough $(<200 \mathrm{~Hz})$. On the other hand, steel structures usually offer really low damping ( $0.2 \%$ in this case), therefore, an increase of damping was sought in order to conserve the ratio $\mathrm{F} / \mathrm{V}$. The increase of damping has been achieved by means of eddy currents, which introduce a pure linear viscous damping without changing other dynamic properties ([23], [24]). For this purpose, a copper plate has been attached to the top of the flexure while permanent magnets have been located in the fixed part. In addition, the exciting force and the vibration measurement are applied near the clamping point of the flexure, where the stiffness is higher, without changing the natural frequency (see Fig. 3). The dynamic behaviour of the designed structure is described in Fig. 4 and Table 1.

Table 1: Dynamic parameters of the structure.

\begin{tabular}{ccc}
\hline$f_{\mathrm{n}}(\mathrm{Hz})$ & $\xi(\%)$ & $k(\mathrm{~N} / \mathrm{m})$ \\
\hline 177.8 & 1.4 & $43.24 \cdot 10^{7}$ \\
\hline
\end{tabular}

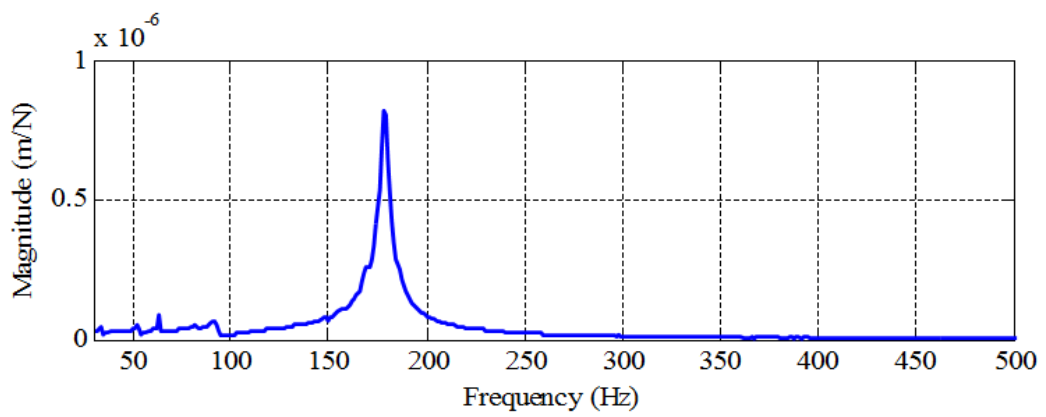

Fig. 4. Frequency Response Function (FRF) of the mechanical structure.

\subsection{Employed equipment}

The equipment used for the implementation of the HIL chatter demonstrator is summarized in 
Fig. 5. The NI CompactRIO has two input signals although only the vibration signal is imperative for the correct operation of the HIL demonstrator. The other signal (applied force sensor) is acquired for information purposes.

A Data Physics V4 shaker has been selected to apply the cutting force. The characterization of the force applied to the structure is exposed in Fig. 6. The F/V ratio has been preserved with a quasi-linear frequency dependency (43 N/V in the vicinity of the natural frequency of the structure). The suspension frequency of the shaker is $11 \mathrm{~Hz}$, which is far enough as not to disturb the behaviour of the HIL. However, if the phase is analysed, a negative slope is observed due to the delay of the system. This delay is an important parameter because it affects the dynamics involved in the regenerative process and, consequently, the stability of the system. This point is specially analysed in section 3.5 .

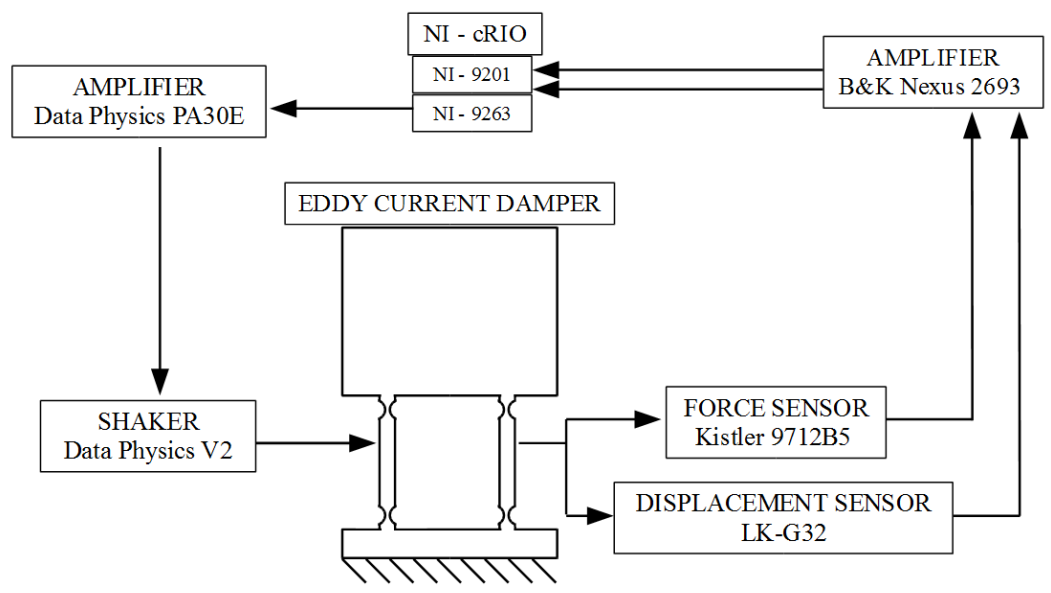

Fig. 5. HIL chatter demonstrator equipment.

The vibration displacement has been measured by using a laser displacement sensor Keyence LK-G32, which has a good signal/noise ratio and does not require any integration, as opposed to an accelerometer. The sampling period has been set to $100 \mu \mathrm{s}$, which is less than 2 degree resolution if the equivalent rotation speed is less than $3000 \mathrm{rpm}$. 
The computation of the chatter model has been implemented on the FPGA Virtex-5 LX 85 of the NI CompactRIO 9022 due to the high timing requirements of the chatter simulation closedloop.

The described HIL chatter demonstrator test bench has been set up out in the laboratory (Fig. 7). Once the regenerative chatter of a machine tool is accurately reproduced on the flexure, a new actuator may be attached to it in order to test the performance of different active control laws [12].
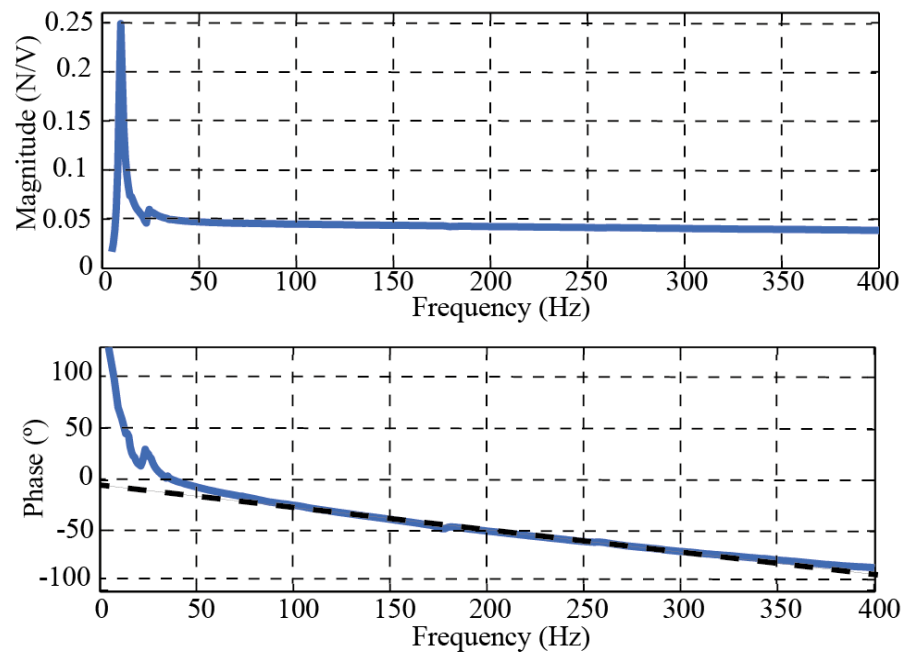

Fig. 6. F/V ratio and phase of the shaker versus frequency.

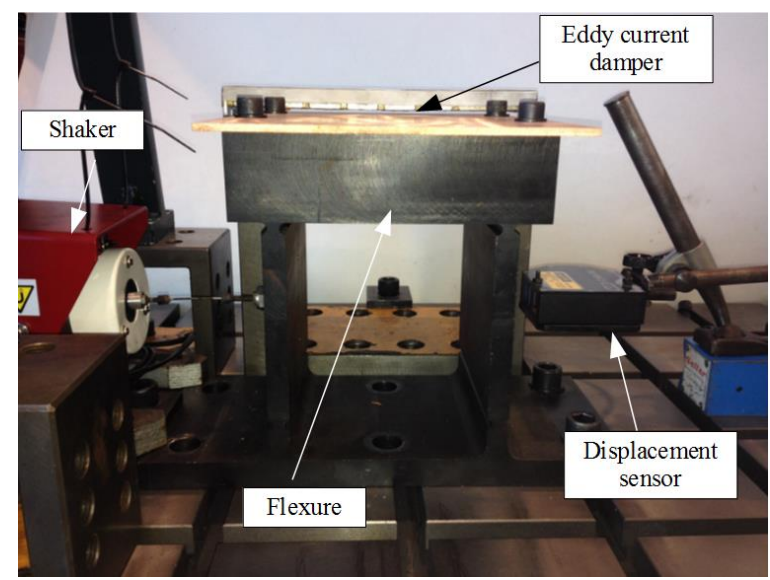

Fig. 7. HIL chatter demonstrator. 


\subsection{Graphical user interface}

As a large number of critical points are needed in order to characterize the stability of different processes, the HIL test bench has been intensively used. For this reason, a practical Graphical User Interface (GUI) has been developed. It has been programmed using LabView ${ }^{\circledR}$ from National Instruments.

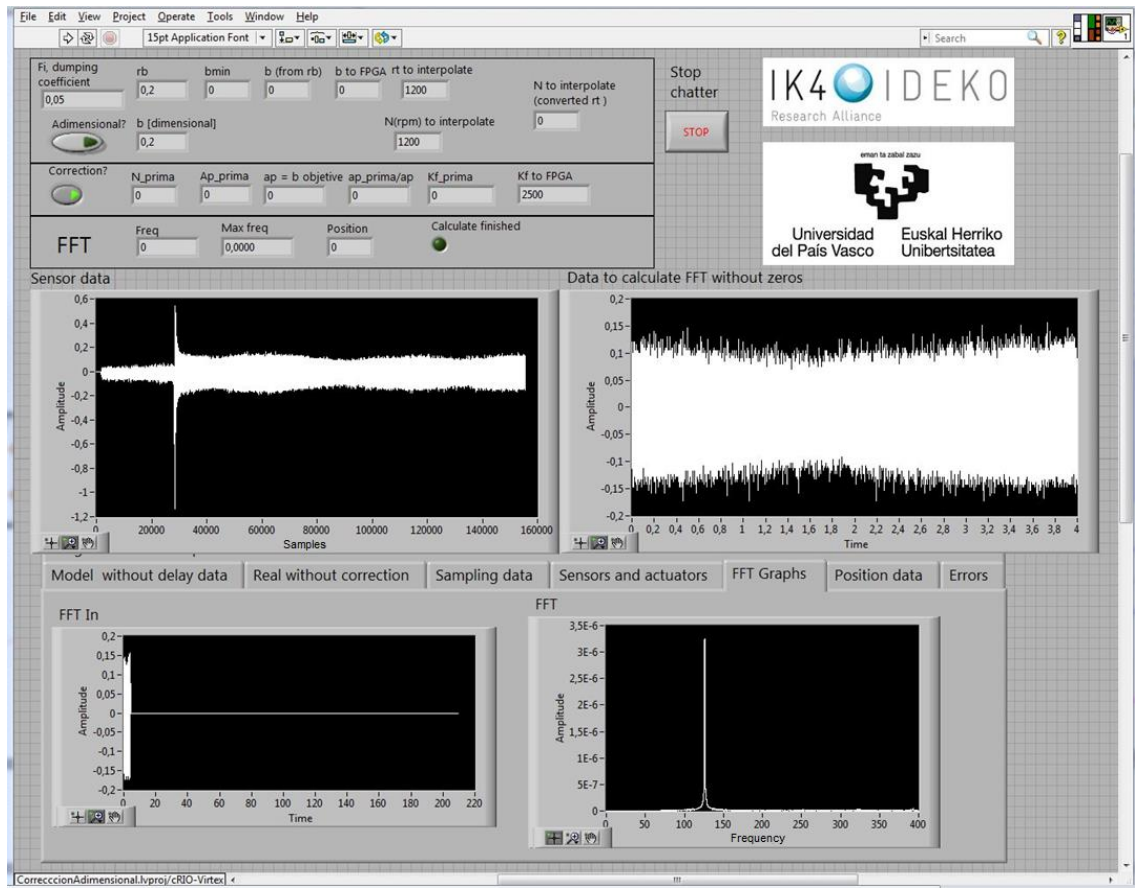

Fig. 8. Screenshot of the graphical user interface (GUI).

Through this interface, the user can select the normalised rotation frequency $\beta$ and the normalised depth of cut $\mu$. According to this data, the temporal evolution of the vibrations is observed in order to decide if the behaviour is stable or not. In this way, the value of $\mu$ can be progressively increased until the unstable vibrations occur. At this moment, the chatter frequency $f_{\mathrm{c}}$ is accurately measured by a Fast Fourier Transform (FFT). Finally, from this chatter frequency $f_{c}$, the normalised chatter frequency $\lambda$ is obtained. The dimensionless stability lobes are obtained 
by scanning the necessary values of $\beta$.

\subsection{Preliminary experimental results}

The regenerative effect model has been tested on the HIL simulator in a dimensionless manner as explained in section 2 . The normalised depth of cut $\mu$ has been increased for different values of the normalised rotation frequency $\beta$, until the vibration became unstable. In this way, the experimental dimensionless stability lobes for the original damping of the structure $(\xi=1.4 \%)$ have been obtained. The experimental results are shown as red crosses in Fig. 9. The normalised chatter frequency at those limiting points is shown in the Fig. 10.

In order to compare experimental and theoretical results, the stability lobes for this structure have also been obtained theoretically, as explained in section 2. Such stability lobes are depicted as a blue solid line in Fig. 9 and Fig. 10. A noticeable deviation which was not pointed out in previous works $([16],[17])$ is observed between experimental and theoretical results. This deviation will be explained and discussed in section 3.5.

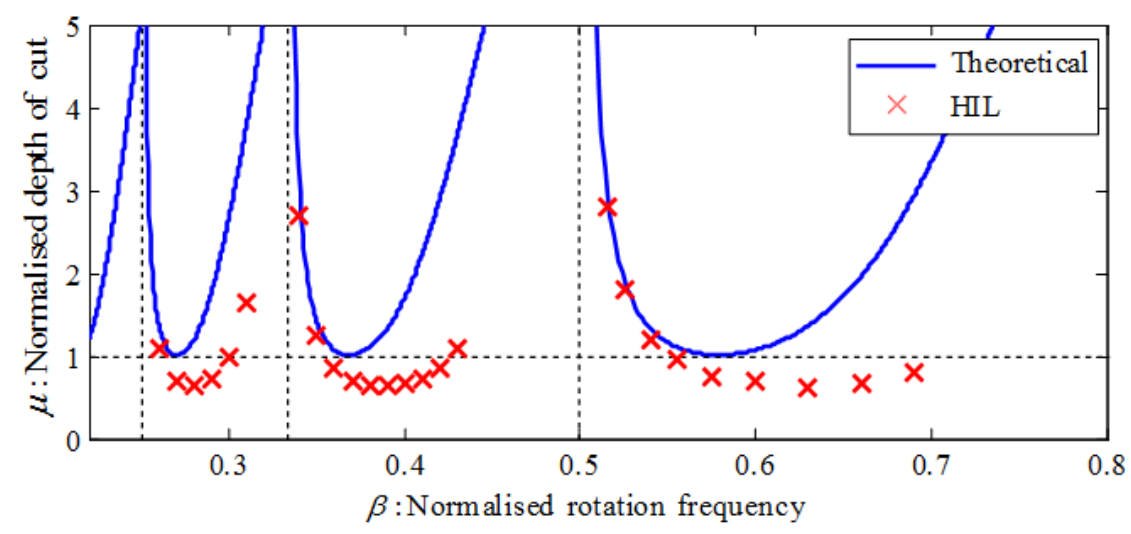

Fig. 9. Theoretical and experimental results: Critical normalised depth of cut. 


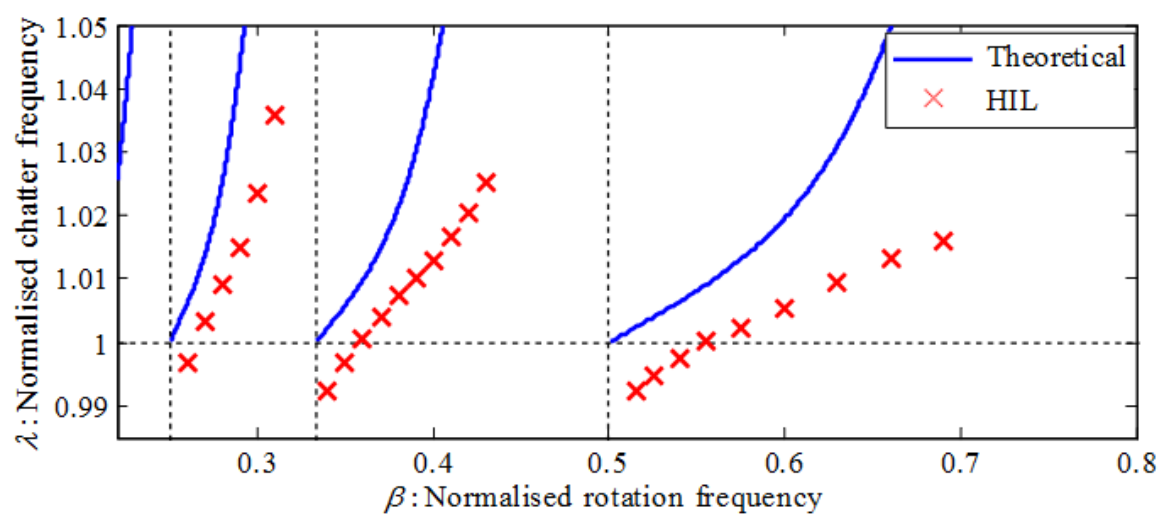

Fig. 10. Theoretical and experimental results: Normalised chatter frequency.

\subsection{System delay modelling}

The delay of the actuation system described in Fig. 6 is put forward as the main source of the discrepancies observed in Fig. 9 and Fig. 10. Such delay occurs due to the phase lag presented by the actuator $\tau_{a}$ and the controller $\tau_{c}$. The controller delay is based on the assumption that the control algorithm computations, including data loading and transmission, will be completed within the sampling period, so the maximum lag time due to the computing cycle is equal to the sampling period [26]. Therefore, the controller delay can be approximated as its sampling period $\left(T_{s}\right)$ and finally, the system delay is the sum of both delays:

$$
\tau_{s y s}=\tau_{a}+\tau_{c} \approx \tau_{a}+T_{s}
$$

In order to confirm this hypothesis, both the actuator delay $\tau_{a}$ and the controller delay $\tau_{c}$ have been considered in the regenerative chatter model. As shown in Fig. 11, $F_{\mathrm{c}}(s)$ is calculated by the controller considering the regenerative effect. Once this force is calculated, it should be divided by the actuator gain $g_{a}$ in order to calculate the voltage signal that is commanded to the shaker amplifier. This signal has a delay, due to the sampling period of the controller $\left(\tau_{c} \approx T_{s}\right)$. From the commanded signal, the amplifier calculates the necessary current to obtain the force $F(s)$ in the 
shaker, which has its own gain defined as the relation between the commanded voltage and the performed force (see Fig. 6). On the other hand, a small delay $\tau_{a}$ exists from the instant of the command of this voltage to the instant at which the force is applied, as it can be observed in the phase plot of Fig. 6 .

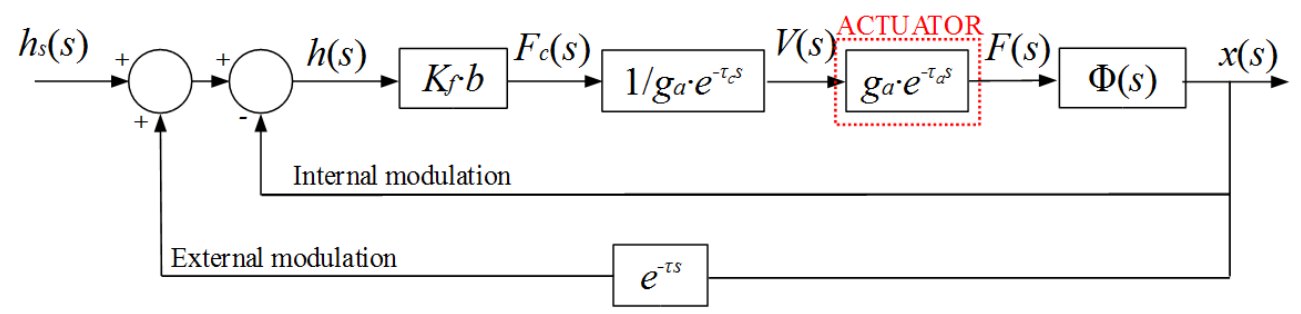

Fig. 11. Closed loop feedback model for regenerative chatter with system delay included.

Taking into account the new block diagram of Fig. 11, the transfer function describing the system is

$$
\frac{x(s)}{h_{s}(s)}=\frac{K_{f} \cdot b \cdot \Phi(s)}{1+K_{f} \cdot b \cdot \Phi(s) \cdot e^{-\tau_{s y s} s}\left(1-e^{-\tau s}\right)}
$$

where $\tau_{s y s}$ is the total delay of the system $\left(\tau_{s y s}=\tau_{a}+\tau_{c}\right)$.

And operating equation (23) in the same way as equation (5) in section 2:

$$
b_{\lim }=\frac{-1}{2 K_{f}\left[G\left(\omega_{\mathrm{c}}\right) \cos \omega_{\mathrm{c}} \tau_{s y s}+H\left(\omega_{\mathrm{c}}\right) \sin \omega_{\mathrm{c}} \tau_{s y s}\right]}
$$

Equation (25) describes the stability limit when the delay of the system is considered. If the normalised depth of cut is calculated now by

$$
\mu=\frac{b_{\lim }}{b_{\min }}=\frac{K_{f} \cdot b_{\lim }}{2 k \xi(1+\xi)}
$$


theoretical dimensionless stability lobes are again obtained and presented by a dashed blue line (see Fig. 12 and Fig. 13).

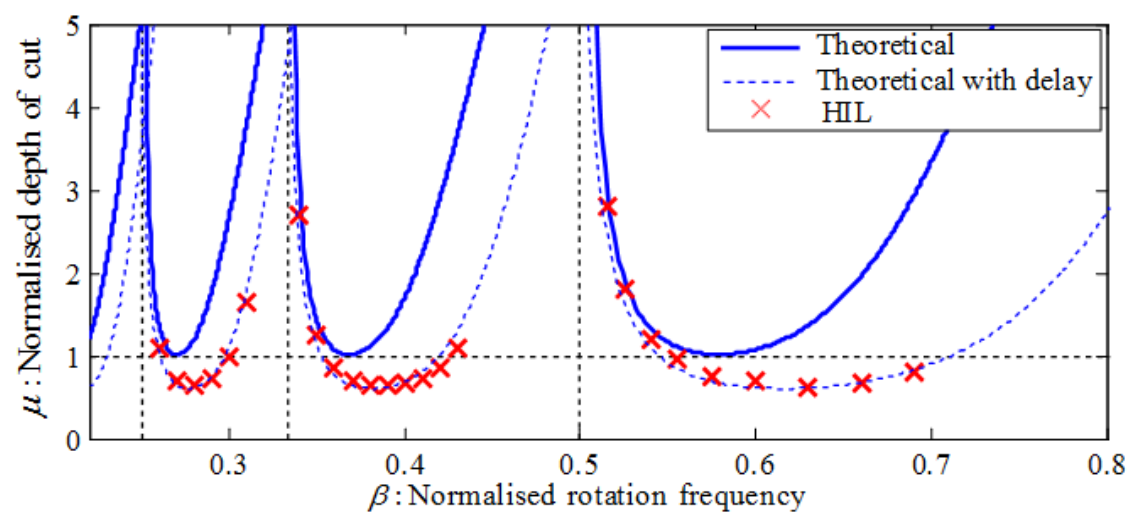

Fig. 12. Theoretical and experimental results with the actuator delay included: Normalised depth of cut.

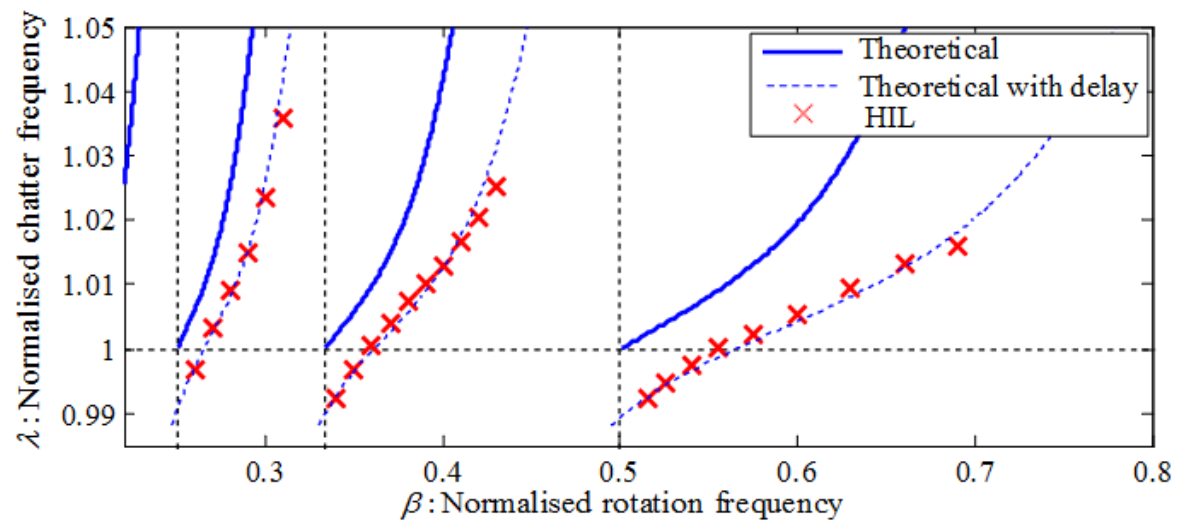

Fig. 13. Theoretical and experimental results with the actuator delay included: Normalised chatter frequency.

As it can be observed, the delay $\tau_{\text {sys }}$ changes drastically the dynamics of the systems. The regenerative effect does not only depend on the real part but on the imaginary part as well, as it happens when the delay does not exist (equation (11)). For this reason, the shape of the stability diagram undergoes important deviations:

- The value of the most stable zone, known as sweet spot, is changed.

- The chatter frequency can be lower than the natural frequency, which is not possible in 
non-delayed systems.

- The minimum depth of cut is changed both in magnitude and in rotation frequency.

- The obtained lobe diagram shows larger instability zones. For instance, three times lower stability is obtained for normalised rotation frequency equal to 0.7 .

Some active control laws are focused on modifying the real part of the frequency response function (FRF) of the system ([7], [17]). Therefore, the delay would have a capital influence in the real analysis of these control laws. These problems make mandatory the compensation of the delay for accurately employing the HIL simulator since a non-compensated HIL does not reproduce the desired regenerative system in a realistic way.

\section{SYSTEM DELAY COMPENSATION AND DAMPING ADJUSTMENT}

As it has been proved in the previous section, the delay of the system is an important drawback in order to reproduce exactly the behaviour of the assumed feedback model of regenerative chatter, especially when the final objective is the analysis of the performance of active control laws.

On the other hand, it is also necessary to adapt the relative damping to simulate the lobe shape of any dynamic behaviour. At this point, it is useful to remark that the main goal is to reproduce, as accurate as possible, the behaviour of any orthogonal cutting of interest on the mechanical structure located in the lab.

Bearing in mind the previous facts, a procedure for the compensation of the system delay and damping is presented below. The flexibility of the HIL demonstrator provided by the system software will be used to compensate the delay imposed by the hardware. 
The method can be divided in two parts: delay compensation by means of a phase lead and damping adjustment by the introduction of a direct velocity feedback control algorithm.

\subsection{System delay compensation}

The effect of the delay introduced by the shaker and the controller sampling period affects the phase around the mechanical resonances. For this reason, the introduction of a filter capable to reshape the frequency response of the system under consideration may solve the mentioned phase distortions. This filter which should be a lead compensator must fulfil two design specifications:

1. Phase compensation around the natural frequency of the structure which causes the chatter effect.

2. Minimal effect in other frequency regions.

The first condition can be easily defined mathematically, when the natural frequency of structure $\omega_{\mathrm{n}}$ and the phase lag introduced by the system $\theta(\omega n)$ are known. The natural frequency of the flexure is $\omega_{\mathrm{n}}=1117.15 \mathrm{rad} / \mathrm{s}(177.8 \mathrm{~Hz})$. According to Fig. 6, the phase lag to compensate is $\theta\left(\omega_{\mathrm{n}}\right)=-0.838 \mathrm{rad}\left(-48^{\circ}\right)$, which means that $\tau_{\text {sys }}=750 \mu \mathrm{s}$. For the considered mechatronic system, the phase lag around the natural frequency is approximated by a linear model (see Fig. 6):

$$
\theta(\omega)=A \omega+B
$$

with $\mathrm{A}=-7.22 \cdot 10^{-4} \mathrm{~s}$ and $\mathrm{B}=-3.14 \cdot 10^{-2} \mathrm{rad}$.

This phase can be introduced by a phase compensator. In this case, the filter is split into two parts to allow a modular design, in order to obtain the desired frequency response shaping. This scheme is represented in Fig. 14. 
The first filter, denoted as $G_{\text {filter } 1}$, is a band-pass filter that gives the necessary phase at the natural frequency. The second one is a stop-band filter $G_{\text {filter } 2}$ which guaranties the stability of the system by minimizing the effect of the filter out of the band around the natural frequency. In order to simplify the design, a base-band filter, considering only the spectrum of frequencies lower than the natural frequency can substitute this stop-band filter. However using this baseband filter, the high frequency components are eliminated. The main advantage of this modular design is the flexibility to include other phase compensators around different natural frequencies, if needed.

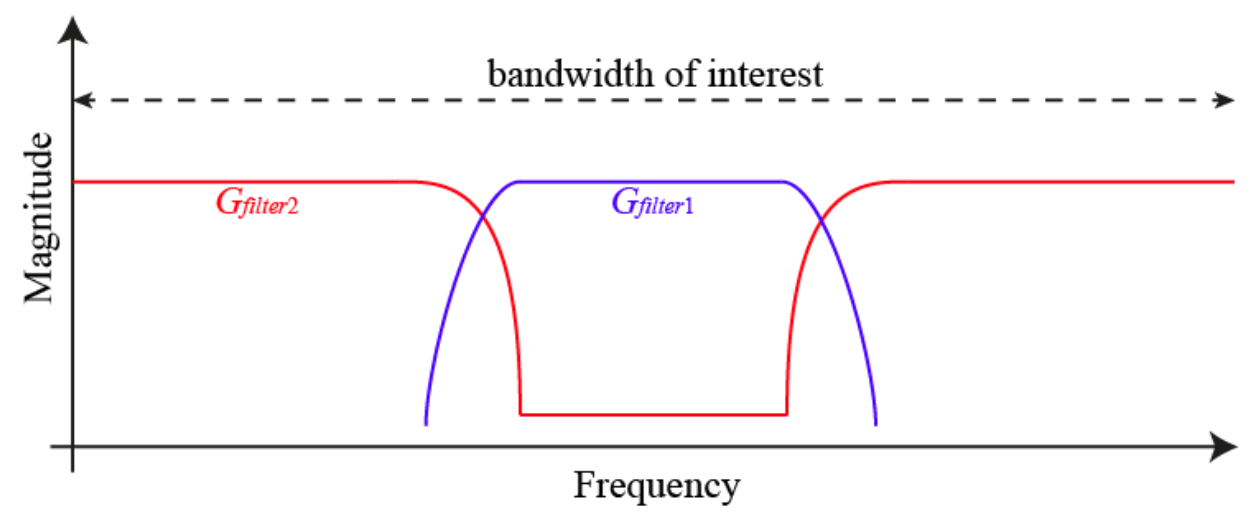

Fig. 14. Modular design of the phase compensation filter.

The band-pass filter is selected as simple as possible to minimize the phase changes for the frequencies of interest and designed to give the necessary phase at $f_{\mathrm{n}}=177.8 \mathrm{~Hz}$. This filter acts as a lead compensator, composed by a dominant zero and a pole. However, the band-pass structure needs another pole defining the upper cut-off frequency. Hence, the structure of this filter is:

$$
G_{\text {filter } 1}(s)=\frac{K_{1}\left(s+z_{1}\right)}{\left(s+p_{1}\right)\left(s+p_{2}\right)}
$$

The design parameters $z_{1}, K_{1}, p_{1}$ and $p_{2}$ are selected for a band-pass of one decade centered around the natural frequency of the structure $(177.8 \mathrm{~Hz})$, with lower cut-off frequency around 
$170 \mathrm{~Hz}$ and upper cut-off frequency around $2500 \mathrm{~Hz}$ :

$$
G_{\text {filter } 1}\left(\mathrm{i} \omega_{\mathrm{n}}\right)=G_{\text {filter } 1}(\mathrm{i} 2 \pi \cdot 177.8)=1 e^{\mathrm{i} \frac{48 \pi}{180}}
$$

giving as result: $p_{1}=1200, p_{2}=2000, z_{1}=20$ and $K_{1}=120000$.

A stop-band filter around $f_{\mathrm{n}}=177.8 \mathrm{~Hz}$ is also needed to avoid variation of the signal at low frequencies is required. In this case, the minimal filter structure needs two poles and two zeros:

$$
G_{\text {filter } 2}(s)=\frac{K_{2}\left(s+z_{2}\right)\left(s+z_{3}\right)}{\left(s+p_{3}\right)\left(s+p_{4}\right)}
$$

Design parameters $p_{3}, p_{4}, z_{2}, z_{3}$ and $K_{2}$ are selected for the required frequency response shaping: minimal effect at low frequencies and attenuation of frequency components around $f_{\mathrm{n}}=177.8 \mathrm{~Hz}$. The stop-band cut-off frequencies are the reverse of the values considered in the design of the first filter, $\left(p_{3}=100, p_{4}=6500, z_{2}=2000, z_{3}=5000\right.$ and $\left.K_{2}=0.065\right)$.

Finally, the phase compensation filter is obtained by the combination of the two filters $G_{\text {filter }}(s)=G_{\text {filter } 1}(s)+G_{\text {filter } 2}(s)$. The design finishes with a model reduction of the resulting transfer function, leading to the next $3^{\text {rd }}$ order filter:

$$
G_{\text {filter }}(s)=\frac{18418.236 s^{2}+5439262.1 s+1977878900}{s^{3}+9100 s^{2}+18900000 s+1800000000}
$$

The Bode diagram of the filter is shown in Fig. 15. The filter response at the resonance frequency adds the necessary phase for compensating the effect of the delay in the system. In addition, the filter provides a small gain at low frequencies to correct the small loss introduced by the shaker. 

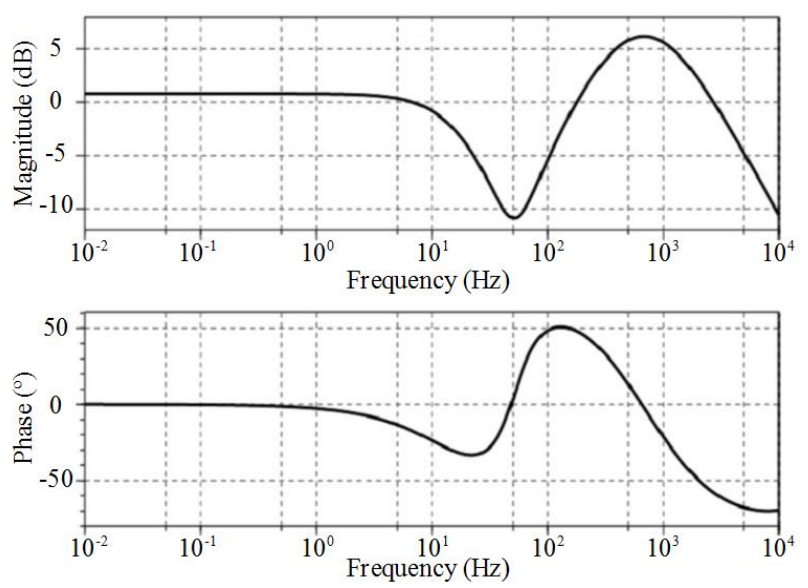

Fig. 15. Bode diagram of the designed lag compensation filter.

The effect of this filter over the frequency response of the system around the resonance frequency can be observed in the Nyquist diagram in Fig. 16.

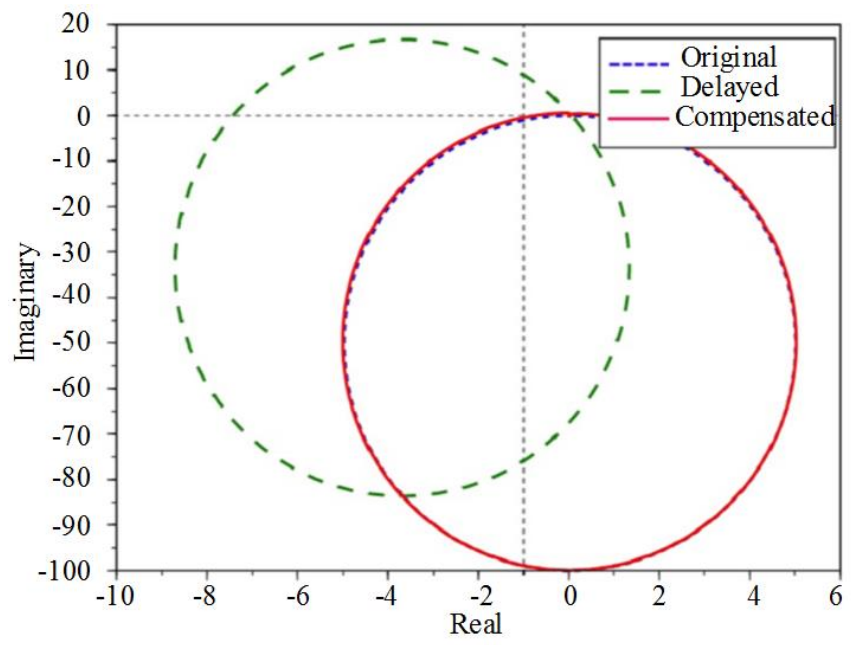

Fig. 16. Nyquist diagram showing the effect of the phase compensation filter.

Finally, the filter presented in equation (31) is discretized by using the bilinear transform and a sampling period of $100 \mu \mathrm{s}$.

$$
G_{\text {filter }}(z)=\frac{0.622246 z^{3}-0.6035 z^{2}-0.6216588 z+0.604142}{z^{3}+2.267642 z^{2}+1.662873 s-0.3940332}
$$

The bode diagram confirms that the performance is sufficiently preserved in the digital 
version. Implementing the phase compensation filter described above into the FPGA of the cRIO and obtaining again the critical values for the normalised depth of cut without any damping compensation, Fig. 17 and Fig. 18 are obtained, where the limiting values and their corresponding frequencies are depicted in red crosses.

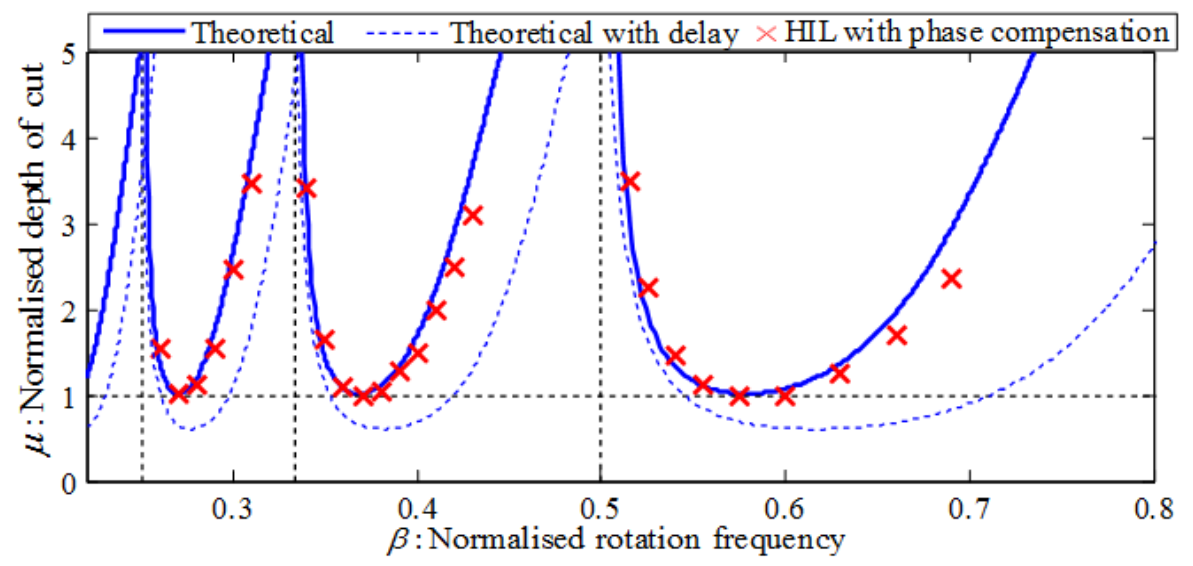

Fig. 17. Compensating the system delay by phase compensation: Normalised depth of cut when $\xi=1.4 \%$.

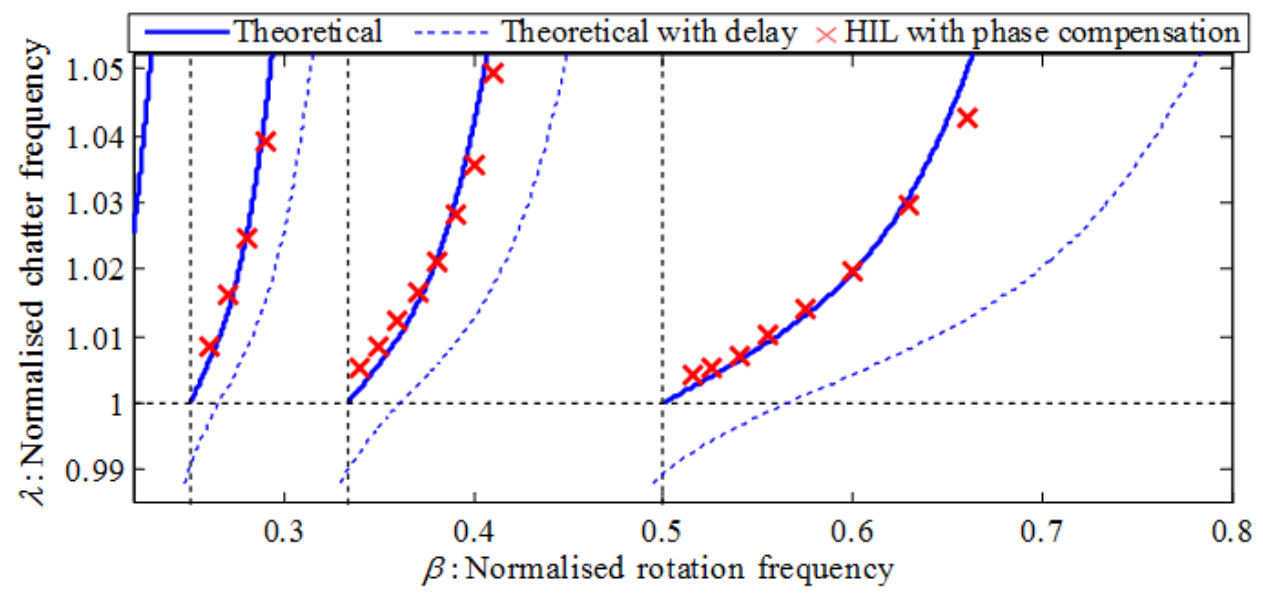

Fig. 18. Compensating the system delay by phase compensation: Normalised chatter frequency when $\xi=1.4 \%$.

The improved correlation of these results with the delay-free lobes is clearly shown. A slight deviation may be observed in the normalised depth of cut and the chatter frequency at high speed lobe regions. The reason for this is that the compensation filter is designed for the natural 
frequency of the structure and when chatter frequency moves away from this frequency, the effectiveness of the filter is reduced.

\subsection{Damping adjustment}

On the other hand, as explained in section 2, it is necessary to adapt the relative damping $\xi$ of the hardware in the loop to be able to reproduce any orthogonal cutting process. A direct velocity feedback (DVF) control algorithm is used, which is the most common control law to increase damping ([15]-[20]). It is based on the measurement of the vibration velocity and its negative feedback is multiplied by a gain $G$.

$$
F_{D V F}(t)=-G \cdot \dot{x}(t)=-g_{a} \cdot g_{v} \cdot \dot{x}(t)
$$

where $g_{a}$ is the actuator gain and $g_{v}$ is the control gain. In this way, the control forces $F_{\mathrm{DVF}}(t)$ appear as viscous damping (see equation (34)) and they are included in the calculation of the force that should be performed by the shaker.

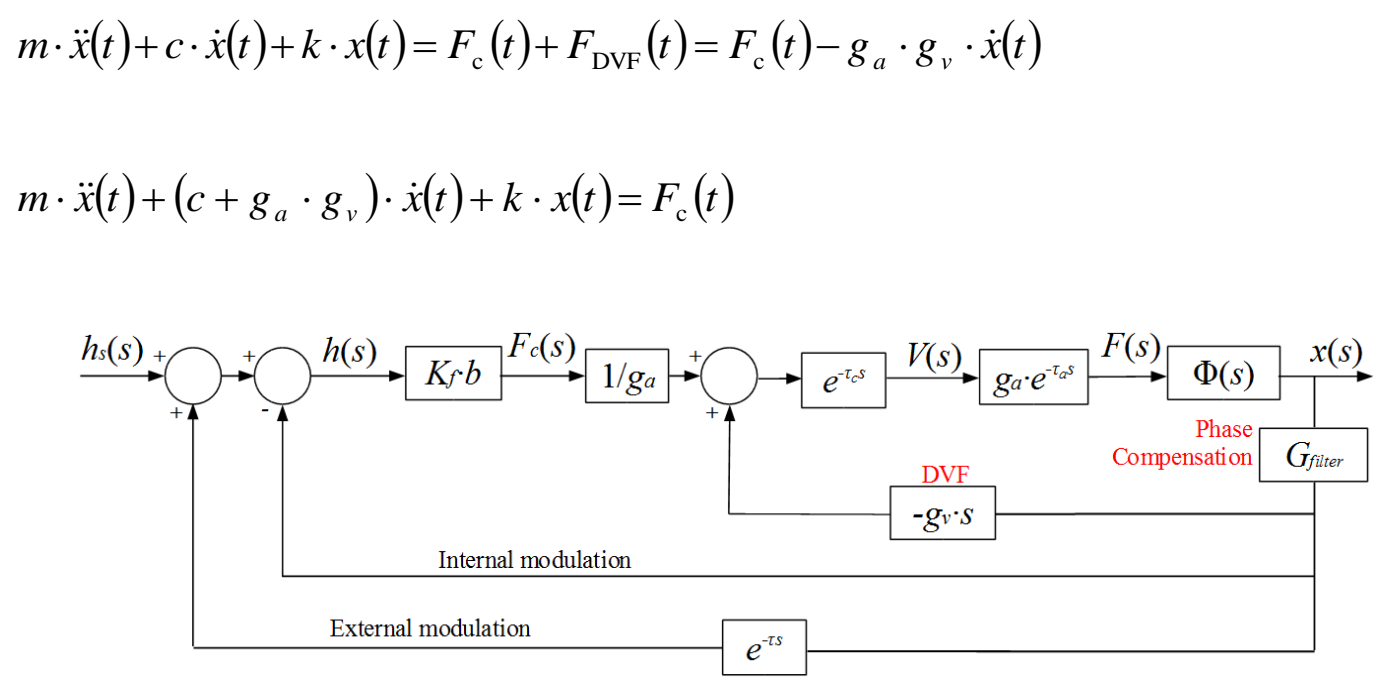

Fig. 19. Control scheme of phase compensation and damping adjustment with DVF method.

To obtain the desired relative damping, the control gain is calculated as: 


$$
g_{v}=\frac{2 \cdot m \cdot \omega_{\mathrm{n}}\left(\xi_{\mathrm{d}}-\xi\right)}{g_{a}}
$$

where $\xi_{\mathrm{d}}$ is the desired relative damping and $\xi$ is the original damping of the hardware-in-theloop $(\xi=1.4 \%)$. Fig. 20 shows the excellent results obtained by the HIL simulator for a virtual damping of $4 \%$.

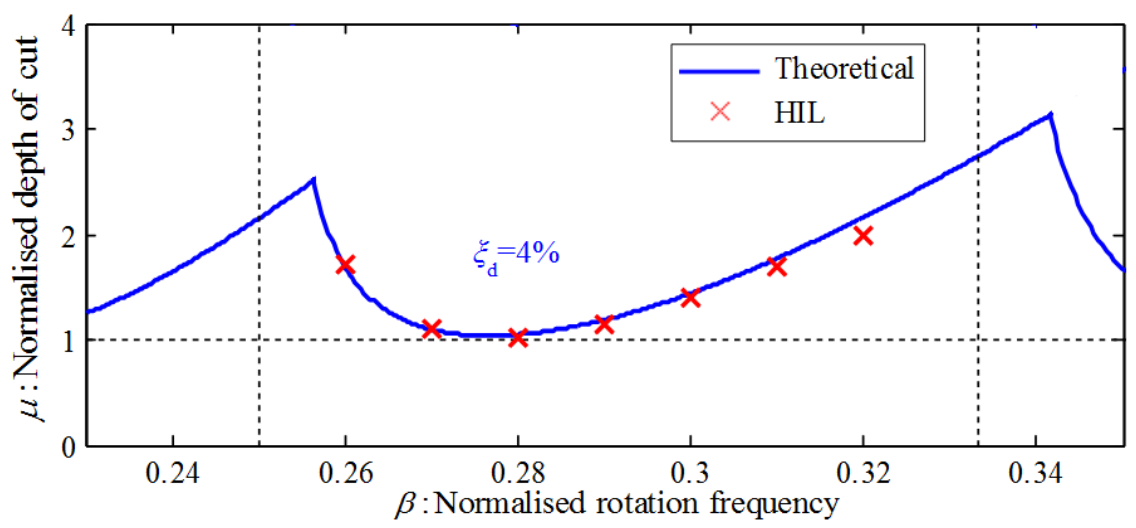

Fig. 20. Delay and damping compensation for $4 \%$ relative damping system.

\section{HIL RESULTS}

In order to verify the HIL simulator, a real lathe machine [21] behaviour is reproduced. The dynamic parameters of this machine and the cutting coefficient are reported on Table 2:

Table 2: Dynamic parameters of the lathe machine used in [21].

\begin{tabular}{cccc}
\hline$f_{\mathrm{n}}(\mathrm{Hz})$ & $\xi(\%)$ & $k(\mathrm{~N} / \mathrm{m})$ & $K_{f}[\mathrm{MPa}]$ \\
\hline 450.7 & 3.8 & $6.48 \cdot 10^{6}$ & 1384 \\
\hline
\end{tabular}

From these dynamic parameters and cutting coefficient, the theoretical dimensionless stability lobes are obtained and compared with the equivalent behaviour reproduced by the HIL. In the 
present paper, the effect of process damping has been neglected in order to simplify the system. Therefore, as explained in section 4, only the delay and damping should be compensated.

Fig. 21 shows the results obtained when applying phase compensation and DVF, defined as red crosses. First, the stability graphs obtained by Altintas et al. [21] have been obtained theoretically and this behaviour has been accurately reproduced by the HIL. Therefore, this HIL simulator could be used in order to perform any cutting test without the necessity of the real machine and workpiece. The presence of process damping increases the depth of cut at high order lobes $\left(k_{u}>10\right)$, therefore a realistic simulation of the process at low spindle speeds requires the introduction of process damping. The reproduction of the process damping effect requires the introduction of a more complex force model in the HIL.

Finally, in order to verify the control applications offered by the HIL simulator, the implementation of active control for suppression of chatter in the HIL simulator has been carried out. If the real machine was used, several cutting test would be required, which would imply material and time wastage. However, the HIL simulator can be used instead of the real machine and a physical active damper can be added to the simulator structure. In this work, the inertial actuator Data Physics V2 is mounted (see Fig. 22 left). The classical Direct Velocity Feedback (DVF) has been applied again, in a new closed loop implemented in an external controller (dSPACE DS-1005 board). Several tests have been carried out, obtaining the results presented as green circles in Fig. 21. The time domain behaviour of the chatter force in point A of Fig. 21 has been captured in Fig. 22. As it can be observed, the dynamic cutting force is considerably reduced when the actuator is switched on and hence, a stable cut is obtained when active damping is applied. 


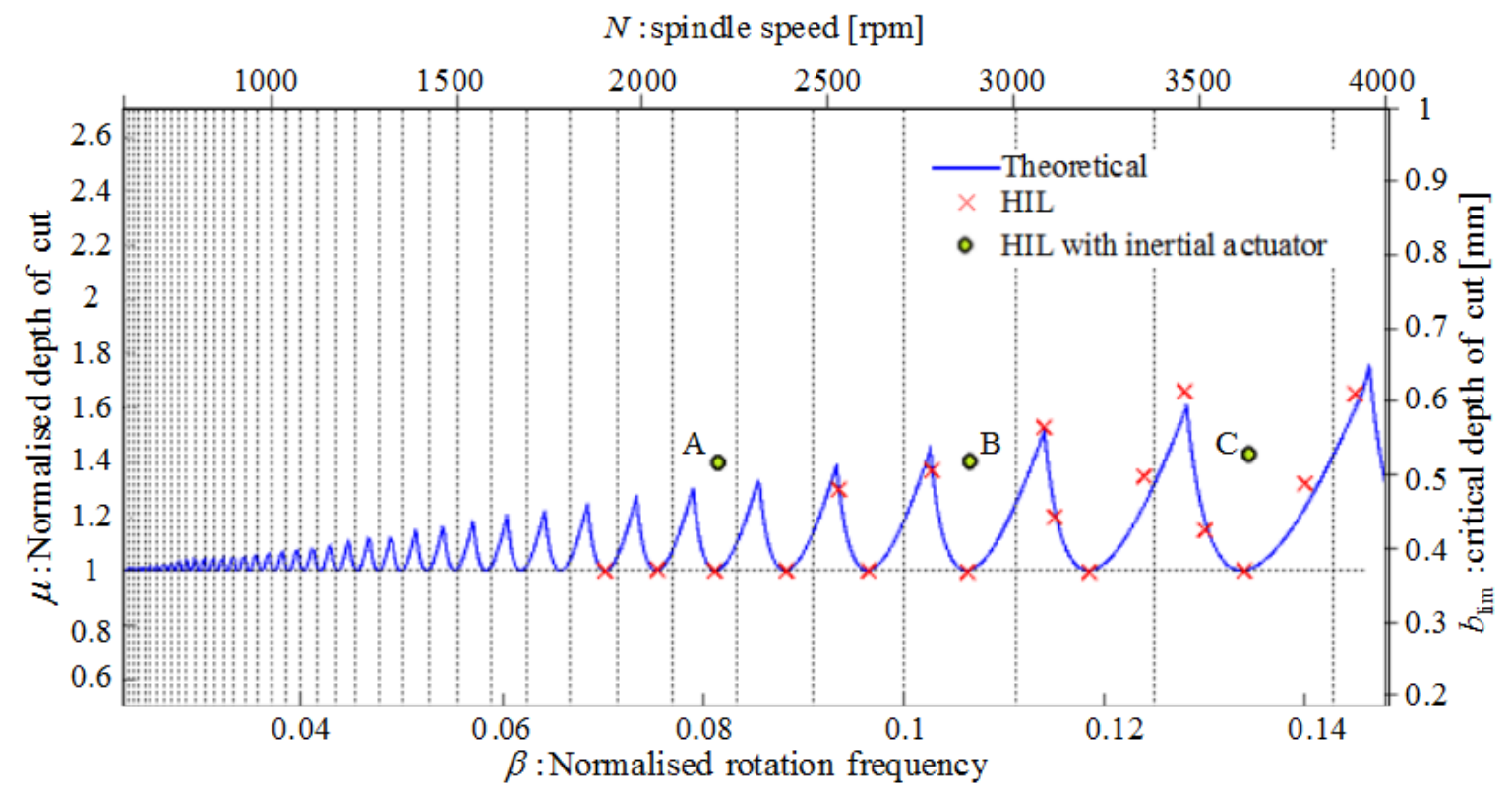

Fig. 21. Simulation by the HIL of the machine defined in Table 2, using the phase compensation and DVF, and the improvement carried out by the inertial actuator.
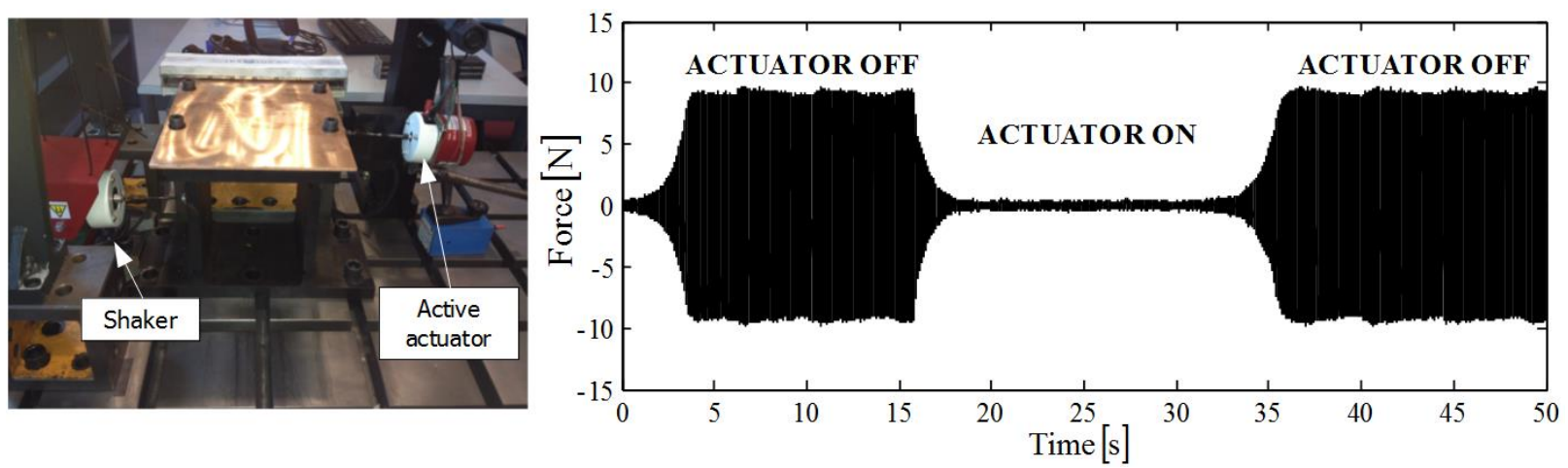

Fig. 22. Left: Addition of the inertial actuator to the HIL for active damping demonstration. Right: Time domain graph of the chatter force in point A test of Fig. 21, where inertial actuator is switched off and switched on.

\section{CONCLUSIONS}

In this work, a complete hardware-in-the-loop (HIL) mechatronic simulator of orthogonal cutting process with regenerative effect has been presented. The experimental study of chatter 
avoidance systems is usually very problematic due to the large number of unavoidable cutting tests and uncertain machining parameters, which can lead to a lack of repeatability in the performed testing. By means of the HIL simulator, the equivalent behaviour of any orthogonal cutting process can be replicated. The simulations are based on a time domain theoretical simulation of chatter but experimental problems such as delays or electrical noise can arise.

A new mechanical structure is proposed for the HIL simulator. Instead of the classic cantilever beam proposed in previous works, a flexure has been designed to ensure a high repeatability. The damping is provided by eddy currents which allow the addition of contactless and linear viscous damping. This linear behaviour improves the performance of the HIL simulator and facilitates the study of different parameters.

Dimensionless formulation is proposed to obtain the equivalence of any orthogonal cutting process on the hardware-in-the-loop (HIL). In this way, the shape of the stability lobes is only altered when damping is changed.

A new methodology implement the required relative damping to the system and compensate the mechatronic system delay is also presented. This delay has tremendous importance and cannot be neglected in order to reproduce the stability accurately. The methodology is based on a phase compensation to remove the delay and a direct velocity feedback (DVF) control loop to fit the required damping. This method, which can be spread to many applications with damping and delay problems, provides very accurate results when compared with theoretical stability lobes.

Finally, a previously published particular case has been accurately reproduced by the proposed HIL simulator. Moreover, it has been used to test successfully an active control law by the addition of a small inertial actuator. In further developments, the process damping phenomenon should be modeled to increase the accuracy in low speed applications. 


\section{ACKNOWLEDGEMENTS}

This work was partially supported by the European Community under the MMTech project (H2020-MG-2014-633776 ) and the Basque Government under PAINT ETORGAI project (ER2012/00019) and REMEC project (IG-2013/0001136).

\section{REFERENCES}

[1] S.A. Tobias, "Machine tool vibrations". Blackie \& Sons Limited, Glasgow, 1965.

[2] J. Tlusty and M. Polacek, "The stability of machine tools against self-excited vibrations in machining". International Research in Production Engineering, pp. 465-474, 1963.

[3] H. E. Merrit, "Theory of self-excited machine-tool chatter-contribution to machine tool chatter research". ASME Journal of Engineering for Industry, vol. 87, no. 4, pp. 447-454, 1965.

[4] Y. Altintas and M. Weck, "Chatter Stability of Metal Cutting and Grinding". CIRP Annals - Manufacturing Technology, vol. 53, no. 2, pp. 619-642, 2004.

[5] J. Munoa, M. Zatarain, Z. Dombovari, and Y.Yang. "Effect of mode interaction on stability of milling processes". Proceedings of the $12^{\text {th }}$ CIRP Conference on Modelling of Machining Operations, San Sebastian, Spain, May 2009.

[6] G. Quintana and J. Ciurana, "Chatter in machining processes: A review”. International Journal of Machine Tools \& Manufacture, vol. 51, pp. 363-376, 2011. 
[7] N.D. Sims, "Vibration absorbers for chatter suppression: A new analytical tuning methodology". Journal of Sound and Vibration, vol. 301, pp. 592-607, 2007.

[8] Y. Yang, J. Munoa, and Y. Altintas, "Optimization of Multiple Tuned Mass Dampers to Suppress Machine Tool Chatter". International Journal of Machine Tools \& Manufacture, vol. 50, no. 9, pp. 834-852, 2010.

[9] A. Cowley and A. Boyle, "Active dampers for machine tools". Annals of the CIRP, vol. 18, pp. 213-222, 1970.

[10] J. Pan, H. Xu, C.M. Kwan, C. Liang, L. Haynes, and Z. Geng, "Modeling and intelligent chatter control strategies for a lathe machine". Control Engineering Practice, vol. 4, no. 12, pp. 1647-1658, 1996.

[11] A. Bilbao-Guillerna, A. Barrios, I. Mancisidor, N. Loix, and J. Muñoa, "Control laws for chatter suppression in milling using an inertial actuator". Proceedings of ISMA 2010 International Conference on Noise and Vibration Engineering, Leuven, Belgium, September 20-22, 2010.

[12] J. Munoa, I. Mancisidor, N. Loix, L.G. Uriarte, R. Bárcena, and M. Zatarain, "Chatter suppression in ram type travelling column milling machines using a biaxial inertial actuator". CIRP Annals - Manufacturing Technology, vol. 62, pp. 407-410, 2013.

[13] J. Monnin, F. Kuster, and K. Wegener, "Optimal control for chatter mitigation in milling - Part 1: Modeling and control design”. Control Engineering Practice, vol. 24, pp. 156-166, 2014. 
[14] J. Monnin, F. Kuster, and K. Wegener, "Optimal control for chatter mitigation in milling - Part 2: Experimental validation". Control Engineering Practice, vol. 24, pp. 167-175, 2014.

[15] I.R. Kendall and R.P. Jones, "An investigation into the use of hardware-in-the-loop simulation testing for automotive electronic control systems". Control Engineering Practice, vol. 7, pp. 1343-1356, 1999.

[16] A. Ganguli, A. Deraemaeker, M. Horondica, and A. Preumont, "Active damping of chatter in machine tools - Demonstration with a "Hardware in the Loop" simulator". Proceedings of the Institution of Mechanical Engineers. Part I: Journal of Systems and Control Engineering, vol. 219, no. 5, pp. 359-379, 2005.

[17] S. Huyanan, "An Active Vibration Absorber for Chatter Reduction in Machining". PhD Thesis, The University of Sheffield, 2007.

[18] A. Ganguli, "Chatter reduction through active vibration damping". PhD Thesis, Université Libre de Bruxelles, 2005.

[19] H.E. Huntley, "Dimensional Analysis". Dover Publications Inc., New York, 1967.

[20] G Stepan, Z Dombovari, J Munoa, "Identification of cutting force characteristics based on chatter experiments". CIRP Annals - Manufacturing Technology, vol. 60, pp. 113-116, 2011.

[21] Y. Altintas, M. Eynian, H. Onozuka, "Identification of dynamic cutting force coefficients and chatter stability with process damping”. CIRP Annals - Manufacturing Technology, vol. 57, pp. 371-374, 2008. 
[22] M. Zatarain, I. Bediaga, J. Munoa, and T. Insperger, "Analysis of directional factors in milling: importance of multi-frequency calculation and the inclusion of the effect of the helix angle". International Journal of Advanced Manufacturing Technology, vol. 47, no. 5-8, pp. $535-542,2010$.

[23] L. Zuo, "Element and system design for active and passive vibration isolation". Phd Thesis, Massachussets Institute of Technology, 2005.

[24] G. Aguirre, M. Gorostiaga, T. Porchez, and J. Munoa, "Self-tuning semi-active tuned mass for machine tool chatter suppression". Proceedings of ISMA 2012 - International Conference on Noise and Vibration Engineering, Leuven, Belgium, September 17-19, 2012.

[25] T. Vyhlídal, W. Michels, P. Zítek, and P. McGahan, "Stability impact of small delays in proportional-derivative state feedback". Control Engineering Practice, vol. 17, pp. 382-393, 2009.

[26] H. Groß, J. Hamann, and G. Wiegärtner, "Electrical Feed Drives in Automation: basics, computation, dimensioning”. Publicis MCD Corporate Publishing, Germany, 2001. 